\title{
Polyploidy Induction of Moth Orchid (Phalaenopsis amabilis (L.) Blume) by Colchicine Treatment on Pollinated Flowers
}

\author{
T. K. K. Azmi ${ }^{1}$, D. Sukma, S. A. Aziz and M. Syukur \\ Received : $28^{\text {th }}$ September 2015 / Accepted : $25^{\text {th }}$ December 2015
}

\begin{abstract}
S
The effectiveness of colchicine treatment at inducing polyploidy in Phalaenopsis amabilis $(2 n=2 x=38)$ was investigated. Colchicine was applied on P. amabilis pollinated flowers and the development of the pods (fruit) was examined. Colchicine concentration in the experiment were 0, 50, 500, 1000, and $2000 \mathrm{mg} \mathrm{L}^{-1}$, with three and five days duration. The result showed that higher colchicine concentration decreased pod length and pod number. Visual screening of the seedlings obtained from colchicines treatments were classified into normal seedlings (NS), i.e. those having similar morphology to control, and putative polyploidy mutant seedlings (PMS). All colchicinetreated PMS were significantly different compared to control in the basal organ of the protocorm (BOP) length and width, leaf length, and root length and diameter. The PMS chromosome number

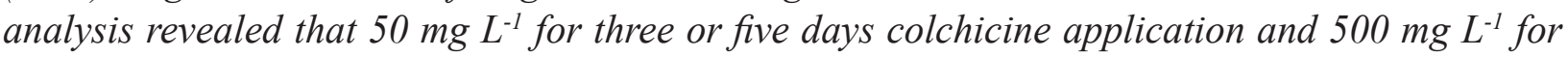
five days colchicine application produced 60 and 100\% tetraploid mutant seedlings, respectively.
\end{abstract}

Keywords: chromosome number, colchicines concentration, pollinated flower, polyploidization

\section{INTRODUCTION}

Phalaenopsis amabilis, one of the species under Phalaenopsis genus, is important in floriculture because of their wide adaptability in various environmental conditions. This species can be found widespread in rain forest of Indonesia to the southern part of Philippines, and east to New Guinea and Queensland, Australia (Christenson, 2001). Phalaenopsis amabilis from South Cianjur, West Java, grows on lowland and has potentials to be developed into new commercial varieties. This $P$. amabilis $(2 n=2 x=38)$ flowers are lack of ornamental qualities and improvement in their flower characters, especially in the flower form and size could increase the ornamental values.

Flower characters of Phalaenopsis are generally one of important aspects that acquire a tremendous attention from orchid breeders and growers. Those of undesired flower characters could possibly be improved by polyploidization. According to Griesbach (1981; 1985), perfection of flower in the white Phalaenopsis types, have probably been achieved by polyploidy. In the recent time, a polyploidy program had developed by Chen et al., (2011b) in Taiwan, to convert over 20 diploid Phalaenopsis species to tetraploid, in order to fill up the needs of the industry. Polyploidy also very important and have been improved various crops characteristics: watermelon (Jaskani et al., (2005), Phlox (Zhang et al., (2008), tomatillo (Torres et al., (2011)), etc. Polyploidy can increase genetic variability and improve flower characteristics, therefore floriculture is probably the most benefited from this technique (Griesbach, 1985). Those of several previous studies have been showed valuable role of polyploidy in orchids and various crops improvement. 
Polyploidy induction by using antimitotic agent is very common technique in polyploidization, one of them that very often used in plant is colchicine (Eigsti and Dustin, 1957). Phaaenopsis Golden Sands is one of several orchid varities that has been obtained by colchicine treatment (Griesbach, 1985). Despite colchicine has been widely used for orchid or various crops polyploidization, an appropriate polyploidy induction protocol with high yielding of desired polypoidy mutant plants is still limited. Effectiveness of polyploidy induction is determined by, among others, plant material used in the treatment. Protocols for polyploidy induction using colchicine have been established on various plant materials. The most often technique and plant material used in orchid polyploidy inductions were protocorm or seedling immersion in aqueous colchicine solution as performed by Griesbach (1981), Chaicharoen and Saejew (1981), Sarathum et al., (2010), Kerdsuwan and Te-chato (2012), and Atichart (2013). However, these in vitro approaches are often laborious and resulted in high percentage of contamination by microorganisms, and also can produced unwanted chimeric plant. In another study, Nakasone (1960) used different orchid plant materials, such as flower spike, seeds, seedling, and cutting, but very few polyploidy plants produced.

Selecting the right plant material is a main key in orchid polyploidization to increase the rate of effectiveness and eliminate chimeric result. In this study, the plant materials used were relatively different with the published studies, that is using pollinated flower for colchicine treatment. This study was conducted to establish a novel and more effective technique in obtaining polyploidy mutant plant of $P$. amabilis. This technique offers several benefits as flower is a reproductive organ which can be easily manipulated by self or cross pollination to generate genetic variation (segregation), and produced progeny with larger quantity of polyploidy mutant seedlings.

\section{MATERIALS AND METHODS}

\section{Plant material and colchicine treatment}

The plant materials used were blooming $P$. amabilis from South Cianjur, West Java, Indonesia. Blooming plants were placed in shaded house and were self pollinated manually. Three days after self pollination, the flowers were castrated to discard their sepals, petals, and labellum. The ovary and stigma of castrated flowers were covered with absorbent cotton, and applied with colchicine solution using small brush until saturated for production of polyploidy seeds/progenies. Colchicine concentrations used in the experiment were 0, 50, 500, 1000, and $2000 \mathrm{mg} \mathrm{L}^{-1}$. Treated colchicine flowers were covered with aluminium foil to prevent evaporation for the duration of three or five days and were nested under each levels of concentration. Colchicine treatments were applied to 1-2 flowers per plant and repeated four times, so there were 40 plants in the experiment.

\section{Pod harvesting and seed sowing}

All of mature pods of colchicine-treated and controls were harvested at 24 weeks after pollination (WAP). The number of harvested pod was counted from each levels of colchicine treatment, and the pod number percentage was calculated by using formula:

$\%$ Pod number $=\frac{\text { Pod number }}{\text { Colchicine treated flower number }} \times 100 \%$

The pod length (the pod with pedicel) was recorded using calipers. All of harvested pods then were rinsed with tap water and the surface was sterilized by dipping into $70 \%(\mathrm{v} / \mathrm{v})$ ethanol for 5 mins followed by passing briefly through the flame for three times. The pods were placed in a sterile petri dish and were cut vertically into two parts. The seeds were cultured on Knudson $\mathrm{C}$ medium supplemented with $2 \%$ $(\mathrm{w} / \mathrm{v})$ sugar, $6 \%(\mathrm{v} / \mathrm{v})$ coconut water, $6 \%(\mathrm{w} / \mathrm{v})$ pineapple and banana, $0.7 \%(\mathrm{w} / \mathrm{v})$ agar and $0.2 \%(\mathrm{w} / \mathrm{v})$ activated charcoal. The cultured 
seeds were incubated at $23{ }^{\circ} \mathrm{C}$ under continous illumination (1000 Lux). The cultured seeds were observed at 8 weeks after showing (WAS) to evaluate the pod number with germinable seeds and the range of protocorm number per pod. In order to observe the quantity of protocorm per pod, the range of protocorm number per pod was classified into three groups, which were high (protocorm $>250$ ), medium $(250>$ protocorm $>50)$, and low (protocorm $<50)$.

\section{Seedling subculture}

Colchicine treatment on pollinated flowers which produced progeny of more than 200 seedlings were subcultured on fresh Knudson C medium, those were $0 \mathrm{mg} \mathrm{L}^{-1}$ (control), $50 \mathrm{mg}$ $\mathrm{L}^{-1}$ for three and five days, and $500 \mathrm{mg} \mathrm{L}^{-1}$ for five days. The seedlings from each colchicine concentration were selected randomly at 15 weeks old after sowing and were subcultured to fresh Knudson C medium with five seedlings per flask. The experiment were arranged in Completely Randomized Design (CRD) with progenies from each colchicines-treated pollinated flowers as treatment, and consisted of five independent replications with five culture flasks per replication. During the growing period of 16 weeks after subculture (WAS), seedlings were observed every two weeks for new leaves and roots. Visual screening, morphological, and anatomical characteristics analysis were assessed at 16 WAS. Screening was conducted visually by comparing its morphological characters similarity and dissimilarity of the progeny seedlings (produced from colchicinetreated pollinated flower) from the diploid control seedling, and then classified them into two group, namely: normal seedling (NS) (similar to control) and the putative polyploidy seedling (PMS) (different to control). Both of seedling group (NS and PMS) then were analized morphologically (measuring the length and width of basal organ of the protocorm (BOP) and leaf, and length and diameter of root) and anatomically (length and width of stomatal) by using calipers and light microscope (40x magnification), respectively.

\section{Cytological analysis of chromosome number}

Both seedling group (NS and PMS) were examined by chromosome number counting to identified polyploidy. Chromosome preparation was determined according to Griesbach (1981) with some modifications. The length of actively growing root tips harvested was about $1 \mathrm{~cm}$. They were then incubated for five hours in $50 \mathrm{mg} \mathrm{L}{ }^{-1}$ colchicine solution at $5-6{ }^{0} \mathrm{C}$ for metaphase arrested. Root tips were rinsed with distilled water and transferred to fixative and hydrolyzed solution of $\mathrm{HCl} 1 \mathrm{~N}$ : glacial acetic acid $(3: 1, \mathrm{v} / \mathrm{v})$ for $3-4$ hours in room temperature. Root tips were stained with $45 \%$ (v/v) aceto-orcein solution for 1-2 hours and transferred on a glass slide then squashed. Root tips samples were taken from five seedlings of each colchicine treatment and its chromosome number were observed under light microscope at 100x magnification with immersion oil.

\section{Statistical analysis}

Data were analyzed by using SAS 9.0. Significant differences of pod number percentage and leaf and root number between treatments were further analyzed using Duncan's Multiple Range Tests (DMRT), comparation of the characters of the putative polyploidy mutant seedlings and the normal seedlings were analyzed using orthogonal contrast at $\mathrm{P}<0.05$.

\section{RESULTS AND DISCUSSION}

\section{Fruit (pod) forming and in vitro seed germination}

The stigma of pollinated flower of $P$. amabilis began to close three days after pollination. The pollinated flowers were able to develop into pod on both control and colchicine treatments. Several pollinated flowers treated with colchicine were not developed and dropped prematurely before they reached harvest time (24 weeks after pollination/WAP). 
Higher colchicine concentrations resulted in shorter pods at 16 WAP (Table 01). Several colchicine-treated pods were dry and dead, especially those treated with 1000 and 2000 $\mathrm{mg} \mathrm{L}^{-1}$ colchicine for both three and five days. Dead pods can be marked by their color which gradually turned to be yellowish green and finally brown. Colchicine effect that hampered the pod development and even dead may caused by toxicity of colchicine that achieved at high concentration (1000 and $2000 \mathrm{mg} \mathrm{L}^{-1}$ ). Nakasone (1960) reported that colchicine treatment in orchid spike caused bud dropped at concentration of 1000 to $10000 \mathrm{mg} \mathrm{L}^{-1}$. Wu et al., (2007) also reported that colchicine treatment to young flower bud of Lilium at $2000 \mathrm{mg} \mathrm{L}^{-1}$ resulted in percentage of death up to 81.3 and $47.0 \%$ in Con Amore and Acapulco varieties, respectively. Toxic effect of colchicine on different plant material was reported by KunHua et al., (2011) on Zingiber shoot bud in vitro, its dead percentage increased significantly at higher colchicine concentration from $10.0 \%$ (1000 $\left.\mathrm{mg} \mathrm{L}^{-1}\right)$ to $83.3 \%\left(4000 \mathrm{mg} \mathrm{L}^{-1}\right)$.

Exposure duration to colchicine treatment, showed that no significance difference between three and five days on pod number percentage produced over all colchicine concentrations. The pod number percentage was significantly affected by colchicine concentration (Figure 01). The pod number percentage decreased at higher colchicine concentration. This result was different to Ghani et al., (2014), survival of Mentha rizhome and tip meristem were affected by both colchicine soaking time and concentration.

All of control pods (eleven pods) produced seeds that could germinate and developed into protocorm on Knudson $\mathrm{C}$ medium. In contrast, only nine out of 25 pods $(36 \%)$ of the colchicinetreated had germinated. Colchicine treatments which produced pods with germinable seeds were $50 \mathrm{mg} \mathrm{L}^{-1}$ for three and five days, 500 $\mathrm{mg} \mathrm{L}^{-1}$ for five days, and $1000 \mathrm{mg} \mathrm{L}^{-1}$ for three days. Treatment of pollinated flowers with higher colchicine concentrations decreased pod number with germinable seeds. Moreover, several pods of colchicine treatment produced very few of non germinable seeds, such as 500 $\mathrm{mg} \mathrm{L}^{-1}$ for three days, $1000 \mathrm{mg} \mathrm{L}^{-1}$ for five days, and $2000 \mathrm{mg} \mathrm{L}^{-1}$ for three and five days. Those conditions indicated that colchicine (especially in high concentration) had affected to the postpollination process and then it may had impacted to the fertilization directly or indirectly.

The range of protocorm number per pod varied between control and colchicine concentrations (Table 01). Colchicine treatment of $500 \mathrm{mg} \mathrm{L}^{-1}$ for five days and $1000 \mathrm{mg} \mathrm{L}^{-1}$ for three days which produced shorter pods than those of controls, had the range of protocorm number per pod at medium $(250>$ protocorm $>50)$ and low (protocorm $<50$ ), respectively. Those results showed that higher colchicine concentrations were not only affected on the appearance of the pod, but also its inside where embryo formation and development occured. It may caused embryo unformed or non-viable embryo formed that impacted to the protocorm number per pod, since the control germination was good/high (protocorm $>250$ ). Colchicine treatment of 50 $\mathrm{mg} \mathrm{L}^{-1}$ for three and five days produced pods with length and protocorm number per pod relatively equal to control. Nakasone (1960) reported that treatment of Vanda and Dendrobium seeds with colchicine of 1000 up to $10000 \mathrm{mg} \mathrm{L}^{-1}$ for more than four days caused interference on their germination. Similar results were also reported in non-orchid plants, in Cyclamen seeds by Takamura and Miyajima (1996) and Platanus acerifolia seeds by Liu et al., (2007). 
Table 01: Pod development characteristics and protocorm produced at different colchicine concentration levels and durations of application

\begin{tabular}{ccccccc}
\hline $\begin{array}{c}\text { Colchicine } \\
\left(\mathrm{mg} \mathrm{L}^{-1}\right)\end{array}$ & Duration & $\begin{array}{c}\text { Colchicine-treated } \\
\text { pollinated flowers } \\
\text { number }\end{array}$ & $\begin{array}{c}\text { Pod } \\
\text { number }\end{array}$ & $\begin{array}{c}\text { Pod length } \\
\text { mean }(\mathrm{cm})\end{array}$ & $\begin{array}{c}\text { Pod number with } \\
\text { germinable seeds }\end{array}$ & $\begin{array}{c}\text { Range of protocorm } \\
\text { number per pod }\end{array}$ \\
\hline 0 & 3 days & 4 & $4 / 4(100.00)$ & 5.12 & $4(100.00)$ & High (protocorm>250) \\
0 & 5 days & 7 & $7 / 7(100.00)$ & 4.92 & $7(100.00)$ & High (protocorm>250) \\
50 & 3 days & 5 & $3 / 5(60.00)$ & 5.26 & $3(100.00)$ & High (protocorm>250) \\
50 & 5 days & 7 & $4 / 7(57.14)$ & 4.52 & $3(75.00)$ & High (protocorm>250) \\
500 & 3 days & 7 & $5 / 7(71.42)$ & 3.52 & $0(0.00)$ & None \\
500 & 5 days & 7 & $6 / 7(85.71)$ & 3.68 & $2(33.33)$ & Medium $(250>$ protocorm $>50)$ \\
1000 & 3 days & 7 & $4 / 7(57.14)$ & 2.80 & $1(25.00)$ & Low (protocorm<50) \\
1000 & 5 days & 7 & $2 / 7(28.57)$ & 2.60 & $0(0.00)$ & None \\
2000 & 3 days & 5 & $1 / 5(20.00)$ & 2.00 & $0(0.00)$ & None \\
2000 & 5 days & 4 & $0 / 4(0.00)$ & 0.00 & $0(0.00)$ & None \\
\hline
\end{tabular}

Pod length was observed about 16 weeks after pollination (WAP).

Protocorm observation was performed at 8 weeks after sowing (WAS).

${ }^{a}=$ value in the brackets showed percentage $(\%)$.

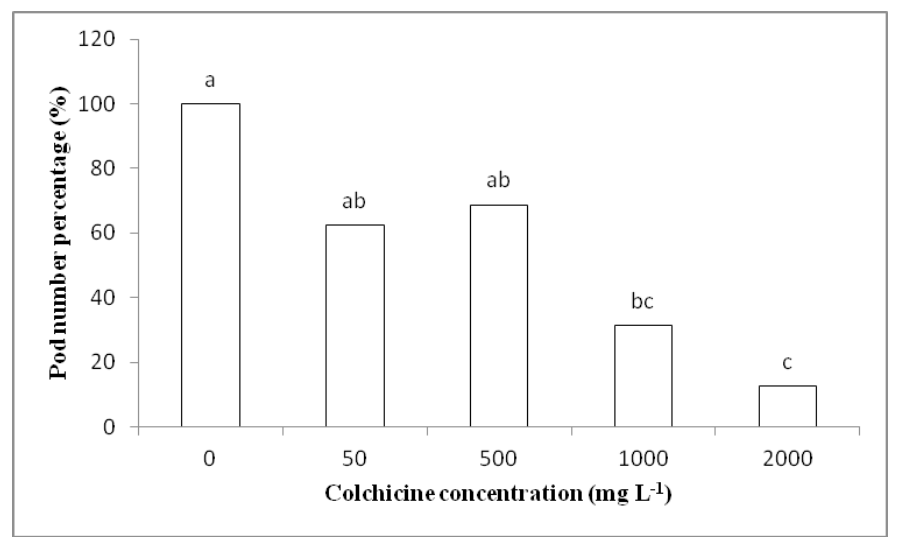

Figure 01: Effect of colchicine concentrations on pod number percentage of $P$. amabilis. Different letters indicate significant difference at $\mathbf{P}<0.05$ according to Duncan's Multiple Range Test (DMRT)

\section{Seedling growth and development}

In general, the seedlings from all colchicine treatments and control showed good growth. New leaves and roots emerged from the seedlings during incubation period up to 16 WAS. However, there was one seedling that showed abnormal morphology which found in colchicine treatment of $500 \mathrm{mg} \mathrm{L}^{-1}$ for five days. The abnormal seedling had no leaves until the end of observation (16 WAS) and appeared as rooted protocorm. Rahayu (2014) also found abnormal seedlings of $P$. amabilis

and $P$. amboinensis which generated from protocorms treated by immersion in colchicine solution, which showed shorter and thicker stem and leaf than its diploid control seedling. Those abnormal seedlings may suspected as an octoploid seedling. As described by Chaicharoen and Saejew (1981) that found the auto-octoploid exhibited abnormalities in both growth and appearance, it grew very slowly and produced only few roots and had thick and wringkled leaf. 
There were significant differences in the leaf and root number of seedlings amongst all colchicine concentration and control during incubation period (Table 02). The seedlings obtained from colchicine treatment of $500 \mathrm{mg} \mathrm{L}^{-1}$ for five days, grew slowly compared to others colchicine treatments including control, with leaf and root number were 0.83 and 0.68 times lower than those of control seedlings respectively, at the end of observation (16 WAS). The variation in the performances of seedlings treated with different colchicine concentrations could be considered as an early indication that colchicine treatment on pollinated flowers of $P$. amabilis was effective in inducing polyploidy mutant seedlings. In general, the polyploidy mutant seedlings obtained by colchicine treatments had slower growth characteristic compared to diploid control seedling (wild type). As observed by Griesbach (1981) that found diploid Phalaenopsis plant grew faster than colchicine-treated tetraploid. Kerdsuwan and Te-chato (2012) also observed similar growth characteristic in Rhynchostylis tetraploid, root number and length were lower than control, but there was an opposite result in leaf number where tetraploid was higher.

Visual screening of the putative polyploidy mutant seedling, cytological identification of the polyploidy mutant seedling, and the percentage of polyploidy mutant seedling

Screening of the putative polyploidy mutant seedling conducted visually by comparing the diploid control seedling and the seedling obtained from colchicine treatments at 16 WAS. There were two types of seedlings as result of screening: normal seedling (NS) and the putative polyploidy mutant seedling (PMS). The NS had morphological characteristics relatively similar to the diploid control seedlings, whereas the PMS were different to diploid control seedlings. Screening of seedlings obtained from colchicine treatment of $50 \mathrm{mg} \mathrm{L}^{-1}$ for three days, $50 \mathrm{mg}$ $\mathrm{L}^{-1}$ for five days, and $500 \mathrm{mg} \mathrm{L}^{-1}$ for five days, resulted the percentage of PMS were 27.35, 39.20 , and $92.80 \%$, respectively.

In this study, there was a character observed that had never been studied in identification of putative polyploidy mutant seedling of $P$. amabilis before, i.e. was basal organ of the protocorm (BOP) on seedling (Figure 02). There were significant differences based on orthogonal contrast test for several characters observed, such as BOP length and width, leaf length, and root length and diameter, between diploid control seedlings and seedlings obtained from all of colchicine treatments (Table 3). Moreover, comparation of those characters observed between the NS and the PMS of all colchicine treatment resulted in significant difference for almost all of characters observed except for leaf width. The PMS of all colchicine treatment had 1.5 times length and width of BOP than the NS. Similar results were recorded from colchicines concentration of $50 \mathrm{mg} \mathrm{L}^{-1}$ for three and five days, and $500 \mathrm{mg} \mathrm{L}^{-1}$ for five days.

Table 02: Leaf and root number mean of seedlings obtained from colchicine treatments of pollinated flowers and control at 4 to 16 weeks after subcultured (WAS)

\begin{tabular}{lcccccccc}
\hline \multirow{2}{*}{ Colchicine } & \multicolumn{2}{c}{4 WAS } & \multicolumn{2}{c}{8 WAS } & \multicolumn{2}{c}{12 WAS } & \multicolumn{2}{c}{16 WAS } \\
\cline { 2 - 9 } & Leaf & Root & Leaf & Root & Leaf & Root & Leaf & Root \\
\hline Control & $1.44 \mathrm{a}$ & $0.90 \mathrm{a}$ & 1.96 & $1.04 \mathrm{ab}$ & $2.47 \mathrm{a}$ & $1.49 \mathrm{a}$ & $3.12 \mathrm{a}$ & $2.06 \mathrm{a}$ \\
$50 \mathrm{mg} \mathrm{L}^{-1}$ (3 days) & $1.17 \mathrm{~b}$ & $0.85 \mathrm{a}$ & 1.79 & $0.97 \mathrm{bc}$ & $2.53 \mathrm{a}$ & $1.48 \mathrm{a}$ & $3.05 \mathrm{ab}$ & $1.96 \mathrm{ab}$ \\
$50 \mathrm{mg} \mathrm{L}^{-1}(5$ days $)$ & $1.46 \mathrm{a}$ & $0.80 \mathrm{ab}$ & 1.97 & $1.05 \mathrm{a}$ & $2.43 \mathrm{a}$ & $1.34 \mathrm{a}$ & $2.83 \mathrm{bc}$ & $1.78 \mathrm{~b}$ \\
$500 \mathrm{mg} \mathrm{L}^{-1}$ (5 days) & $1.41 \mathrm{a}$ & $0.68 \mathrm{~b}$ & 1.79 & $0.94 \mathrm{c}$ & $2.21 \mathrm{~b}$ & $1.16 \mathrm{~b}$ & $2.60 \mathrm{c}$ & $1.42 \mathrm{c}$ \\
\hline
\end{tabular}

Means followed by different letter within the same columns indicate significant difference at $\mathrm{P}<0.05$ according to Duncan's Multiple Range Test (DMRT).

Sample size of each colchicine treatment and control were 125 seedlings, except in $50 \mathrm{mg} \mathrm{L}^{-1}$ colchicine (3 days) with 117 seedlings at 8-16 weeks after subcutured (WAS). 


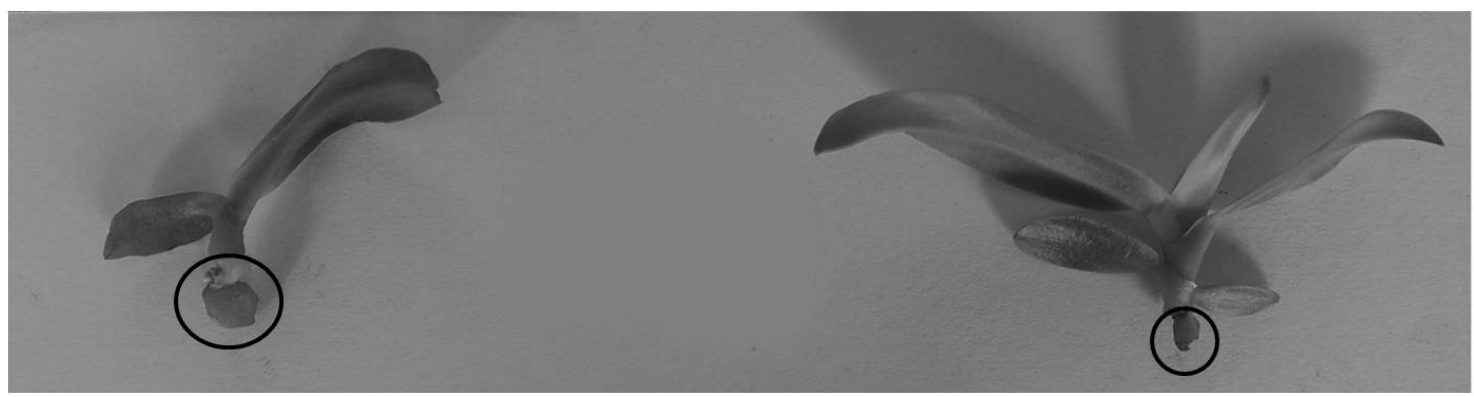

Figure 02: Basal organ of the protocorm (BOP) sizes on seedlings at $500 \mathrm{mg} \mathrm{L}^{-1}$ colchicine (5 days colchicine application). The putative polyploidy mutant seedling (left) and the normal seedling (right)

However, the morphologicals changed of the PMS were not always higher than both control and the NS as observed in leaf and root length of seedling (Table 03). Alteration of colchicine-treated polyploidy was varied or species dependent and it may was not always appeared in gigantic form, especially at in vitro condition. Similarly with Chen et al., (2009) that observed leaf length of tetraploid $P$. hieroglyphica was significantly lower than its diploid. However, Heping et al., (2008), found that significant different in widht and length of Dioscorea leaf with higher values of tetraploid than their diploid were only at in vivo condition (no significant different at in vitro condition). The most common characteristic changed of polyploidy was gigantic form or darken leaf color. Chaicharoen and Saejew (1981) found some characteristics changed of tetraploid Dendrobium which were greener and thicker leaf than their diploid. Those leaf characters changed were also found by Omidbaigi et al., (2010) in basil (non-orchid). Jaskani et al., (2005) observed gigantic form of tetraploid watermelon leaf with higher leaf area index than diploid counterparts. Torres et al., (2011) discovered tomatillo polyploid showed higher plant height and fruit weight and diameter. Zhang et al., (2008) found tetraploid Phlox flower with higher size but lower leaf length.

Anatomical observation revealed that the PMS of all colchicine treatment had both length and width of abaxial stomatal significantly larger (1.12 and 1.17 times, respectively) than the
NS. Similar results also occurred in colchicine concentration of $500 \mathrm{mg} \mathrm{L}^{-1}$ for five days (Figure 03). These results were in accordance with some orchid studies of tetraploid seedlings which were obtained by colchicine treatments, by Chen et al., (2009), Kerdsuwan and Techato (2012), and Rahayu (2014), as well as in non-orchid plants such as in Anthurium by Chen et al., (2011a) and in Citrus nobilis by Yulianti et al., (2014). Stomatal size was often used as indirect polyploidy identification as performed by Miguel and Leonhardt (2011) that used stomatal length comparation to identify polyploidy in some orchids.

The chromosome number of the NS and PMS of each colchicine concentration were examined using a light microscope to confirm ploidy levels. The result showed that the NS of each colchicine concentration were $100 \%$ diploid $(2 n=2 x=38)$. All of colchicine concentration of $50 \mathrm{mg} \mathrm{L}^{-1}$ for three and five days, and 500 $\mathrm{mg} \mathrm{L}^{-1}$ for five days were effective in obtaining polyploidy mutant seedlings. Colchicine at 50 $\mathrm{mg} \mathrm{L}^{-1}$ for three and five days had percentage of polyploidy mutant seedling $60 \%$ of the overall PMS examined. The highest percentage of polyploidy mutant seedling obtained from colchicine concentration of $500 \mathrm{mg} \mathrm{L}^{-1}$ for five days, with all of PMS examined were identified as polyploidy mutant seedlings (100\%) (Table 04). The chromosome number of diploid control and tetraploid mutant seedling of $P$. amabilis were presented in Figure 4. 
Table 03: Comparison of some characters of seedlings obtained from colchicine treatments of pollinated flowers and control at 16 weeks after subcultured (WAS)

\begin{tabular}{|c|c|c|c|c|c|c|c|c|}
\hline & \multicolumn{2}{|c|}{$\mathrm{BOP}^{\mathrm{a}}$} & \multicolumn{2}{|c|}{ Leaf $^{a}$} & \multicolumn{2}{|c|}{$\operatorname{Root}^{\mathrm{a}}$} & \multicolumn{2}{|c|}{ Stomatal $^{\mathrm{b}}$} \\
\hline & $\begin{array}{l}\text { Length } \\
(\mathrm{mm})\end{array}$ & $\begin{array}{l}\text { Width } \\
(\mathrm{mm})\end{array}$ & $\begin{array}{l}\text { Length } \\
(\mathrm{cm})\end{array}$ & $\begin{array}{l}\text { Width } \\
(\mathrm{cm})\end{array}$ & $\begin{array}{l}\text { Length } \\
(\mathrm{cm})\end{array}$ & $\begin{array}{l}\text { Diameter } \\
(\mathrm{mm})\end{array}$ & $\begin{array}{c}\text { Length } \\
(\mu \mathrm{m})\end{array}$ & $\begin{array}{l}\text { Width } \\
(\mu \mathrm{m})\end{array}$ \\
\hline Control & 2.19 & 1.73 & 3.32 & 0.7 & 4.27 & 1.49 & 29.04 & 29.47 \\
\hline All colchicine treatment & 3.26 & 2.26 & 2.48 & 0.68 & 3.5 & 1.79 & 30.54 & 28.48 \\
\hline Contrast test & $*$ & $*$ & $*$ & ns & $\mathrm{ns}$ & * & $\mathrm{ns}$ & ns \\
\hline Control & 2.19 & 1.73 & 3.32 & 0.7 & 4.27 & 1.49 & 29.04 & 29.47 \\
\hline PMS (all colchicine treatment) & 3.91 & 2.66 & 2.29 & 0.67 & 2.96 & 1.87 & 32.24 & 30.77 \\
\hline Contrast test & $*$ & $*$ & $*$ & ns & $*$ & * & ns & ns \\
\hline NS (all colchicine treatment) & 2.61 & 1.86 & 2.67 & 0.68 & 4.05 & 1.72 & 28.83 & 26.19 \\
\hline PMS (all colchicine treatment) & 3.91 & 2.66 & 2.29 & 0.67 & 2.96 & 1.87 & 32.24 & 30.77 \\
\hline Contrast test & $*$ & $*$ & $*$ & ns & $*$ & * & $*$ & $*$ \\
\hline NS (50 mg L-1 3 days) & 2.49 & 1.79 & 2.88 & 0.74 & 4.71 & 1.73 & 28.83 & 26.24 \\
\hline PMS (50 mg L L $^{-1} 3$ days) & 3.61 & 2.4 & 2.31 & 0.63 & 3.15 & 1.73 & 29.07 & 29.71 \\
\hline Contrast test & $*$ & $*$ & $*$ & $*$ & $*$ & ns & ns & ns \\
\hline NS (50 mg L-1 5 days) & 2.41 & 1.78 & 2.97 & 0.66 & 4.19 & 1.56 & 27.98 & 24.53 \\
\hline PMS (50 mg L ${ }^{-1} 5$ days) & 3.28 & 2.31 & 2.59 & 0.6 & 3.34 & 1.45 & 31.56 & 28.9 \\
\hline Contrast test & $*$ & $*$ & ns & ns & ns & ns & ns & * \\
\hline NS (500 mg L $\mathrm{m}^{-1} 5$ days) & 2.94 & 2.02 & 2.15 & 0.66 & 3.25 & 1.86 & 29.68 & 27.79 \\
\hline PMS (500 mg L-1 5 days) & 4.83 & 3.27 & 1.97 & 0.79 & 2.39 & 2.44 & 36.1 & 33.69 \\
\hline Contrast test & $*$ & $*$ & $\mathrm{~ns}$ & $*$ & $\mathrm{~ns}$ & $*$ & $*$ & $*$ \\
\hline
\end{tabular}

$\mathrm{NS}=$ the normal seedling, PMS = the putative polyploidy mutant seedling.

No significant different (ns) and significantly different $(*)$ according to contrast test at $\mathrm{P}<0.05$.

${ }^{a}$ Five seedling per colchicine treatment and control samples with five replications.

${ }^{\mathrm{b}}$ Three different spot view per leaf per colchicine treatment and control samples with five replications. Stomatal were observed using light microscope with 100x magnification.

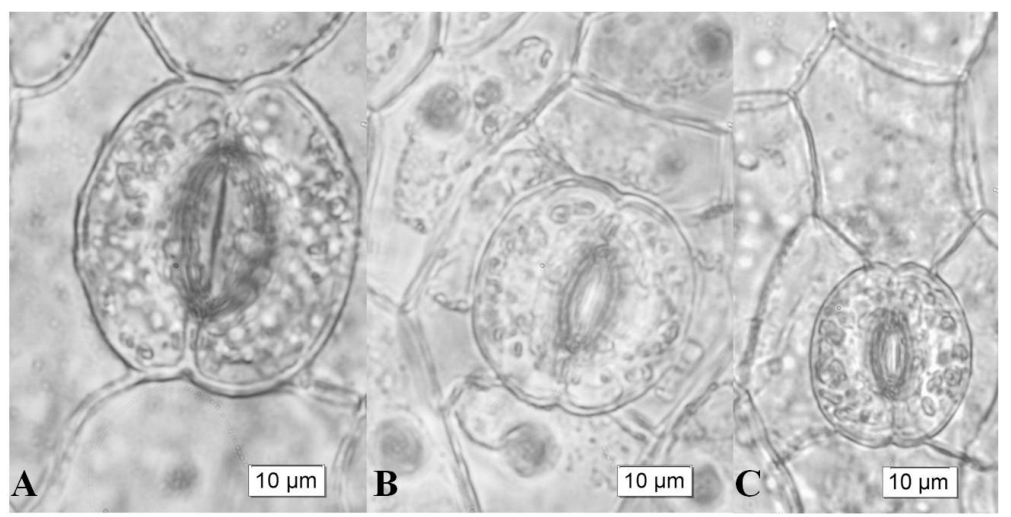

Figure 03: Stomatal sizes of abaxial leaf at $500 \mathrm{mg} \mathrm{L}^{-1}$ colchicine (5 days colchicine application), a. the putative polyploidy mutant seedling, b. the normal seedling, and c. control seedling 
Table 04: Effectiveness of colchicine treatments on pollinated flower of $P$. amabilis at inducing poliploidy

\begin{tabular}{|c|c|c|c|c|c|}
\hline Colchicine & $\begin{array}{l}\text { Seedling } \\
\text { type }\end{array}$ & $\begin{array}{c}\text { Number of } \\
\text { seedling examined }\end{array}$ & $\begin{array}{l}\text { Number of } \\
\text { diploid seedling }\end{array}$ & $\begin{array}{c}\text { Number of } \\
\text { polyploidy seedling }\end{array}$ & $\begin{array}{r}\text { Percentage of } \\
\text { polyploidy }(\%)\end{array}$ \\
\hline Control & NS & 5 & 5 & 0 & 0 \\
\hline \multirow[t]{2}{*}{$50 \mathrm{mg} \mathrm{L}^{-1}$ (3 days) } & NS & 5 & 5 & 0 & 0 \\
\hline & PMS & 5 & 2 & 3 & 60 \\
\hline \multirow[t]{2}{*}{$50 \mathrm{mg} \mathrm{L}^{-1}$ (5 days) } & NS & 5 & 5 & 0 & 0 \\
\hline & PMS & 5 & 2 & 3 & 60 \\
\hline \multirow[t]{2}{*}{$500 \mathrm{mg} \mathrm{L}^{-1}$ (5 days) } & NS & 5 & 5 & 0 & 0 \\
\hline & PMS & 5 & 0 & 5 & 100 \\
\hline
\end{tabular}

$\mathrm{NS}=$ the normal seedling, PMS $=$ the putative polyploidy mutant seedling

Counting of chromosome number was performed after 16 weeks after subcultured (WAS)

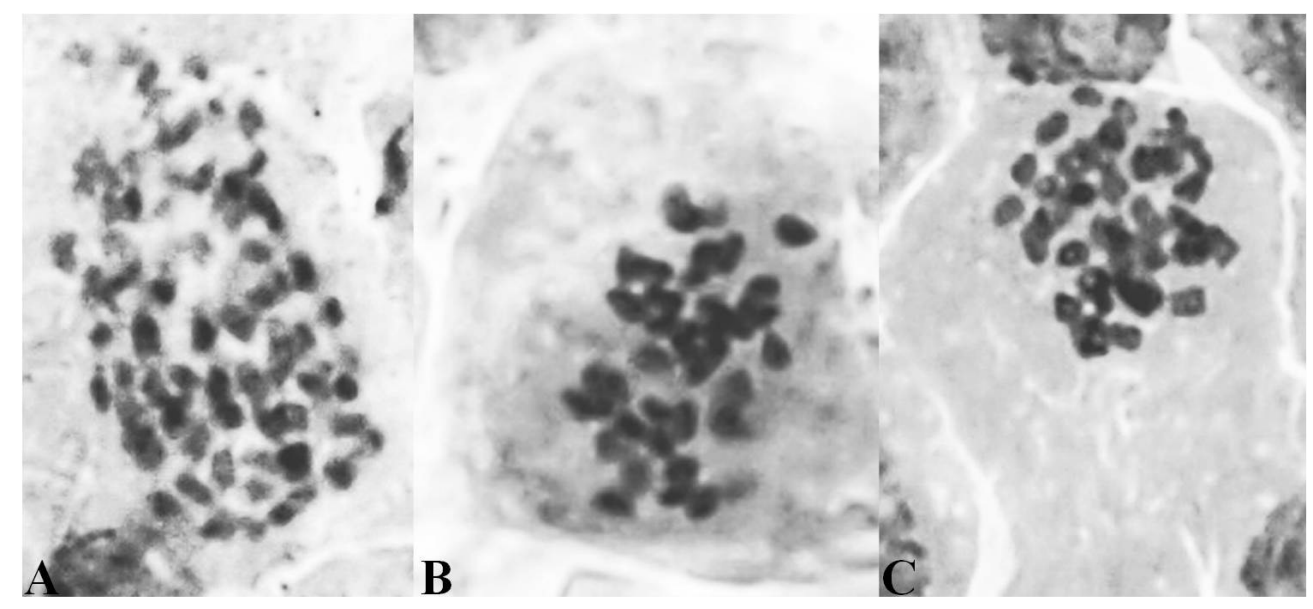

Figure 04: Somatic chromosomes from root tip seedlings of $P$. amabilis: a. polyploidy mutant seedling $(2 n=4 x=76)$ and $b$. normal seedling $(2 n=2 x=38)$ from colchicine treatment at $500 \mathrm{mg} \mathrm{L}^{-1}$ ( 5 days colchicine application), and c. control seedling $(2 n=2 x=38)$ (100x magnification)

The cytological examinations proved that colchicine treatment on pollinated flowers of $P$. amabilis was effective in producing progeny of polyploidy mutant seedlings. Another research that used orchid generative organ also was conducted by Nakasone (1960) which used young flower spike of Vanda as a material for colchicine treatment, but no polyploidy seedling produced in the study. In non-orchid plants, $\mathrm{Wu}$ et al., (2007) reported the polyploidy induction in Lilium obtained $18 \%$ triploid mutant progeny by crossing colchicine-treated flowers with diploid control flowers. Other orchid studies with colchicine treatment on protocorm reported by Chaicharoen and Saejew (1981) and Griesbach (1981), also resulted in approximately 50\% tetraploid mutants. Sarathum et al., (2010) and Kerdsuwan and Te-chato (2012) reported the percentage of tetraploid mutant orchid were 43 and $60 \%$, respectively. Polyploidy induction in non-orchid plant resulted in 50\% polyploidy mutant in Platycodon grandiflorus (Wu et al., 2011). Chimeric result of polyploidy induction also has been reported by Petersen et al., (2003) that found high percentage of ploidy chimeras in colchicine-treated planlet of Miscanthus. 


\section{CONCLUSIONS}

Colchicine treatments on pollinated flowers of $P$. amabilis were effective in obtaining a high number of polyploidy mutant seedlings (progenies). The length of pod and percentage of pod number were inhibited by colchicine treatment at higher concentration. Visual screening of seedlings (especially for basal organ of the protocorm character) obtained from colchicine treatments was effective in sorting polyploidy mutant seedlings from its diploid seedlings. Colchicine at $500 \mathrm{mg} \mathrm{L}^{-1}$ for five days was the most effective treatment for polyploidy induction, this treatment resulted $100 \%$ of putative polyploidy mutant seedlings were tetraploid.

\section{ACKNOWLEDGEMENT}

This research was supported by Decentralization Competitive Grant of Directorate General of Higher Education, Ministry of Education and Culture, Indonesia, in 2013-2014.

\section{REFERENCES}

Atichart, P. (2013). Polyploid induction by colchicine treatments and plant regeneration of Dendrobium chrysotoxum, Thai Journal of Agricultural Science. 46(1): pp. 59-63.

Chaicharoen, S. and Saejew, K. (1981). Autopolyploidy in Dendrobium phalaenopsis, Jounal of The Science Society of Thailand. 7: 25-32. http://scienceasia. org/1981.07.n1/v07_025_032. pdf. 03.12.2012.

Chen, C., Hou, X., Zhang, H., Wang, G. and Tian, L. (2011a). Induction of Anthurium andraeanum "Arizona" tetraploid by colchicine in vitro, Euphytica. 181: pp. 137-145. http://dx.doi. org/10.1007/s10681-010-0344-3. 09.09.2014.

Chen, W.H., Tang, C.Y. and Kao, Y.L. (2009). Ploidy doubling by in vitro culture of excised protocorms or protocorm-like bodies in Phalaenopsis spesies, Plant Cell Tissue and Organ Culture. 98: pp. 229-238. http://dx.doi.org/10.1007/s11240-009-9557-3. 03.12.2012.

Chen, W.H., Kao, Y.L., Tang, C.Y. and Jean, G.T. (2011b). Endopolyploidy in Phalaenopsis orchids and its application in polyploid breeding. In: Orchid Biotechnology II (Chen, W.H. and Chen, H.H. Eds). World Scientific, Singapore. pp. 25-48.

Christenson, E.A. (2001). Phalaenopsis: A Monograph. Timber Press, Oregon.

Eigsti, O.J. and Dustin, P. (1957). Colchicine in Agriculture, Medicine, Biology, and Chemistry. Iowa State College Pr, Iowa.

Ghani, A., Neamati, S.H., Azizi, M., Saharkhiz, M.J., Farsi, M. (2014). Artificial autotetraploidy induction possibility of two Iranian endemic Mint (Mentha mozaffarianii) ecotypes, Notulae Scientia Biologicae. 6(2): pp. 185-191. http://dx.doi.org/10.15835/nsb.6.2.9129

Griesbach, R.J. (1981). Colchicine-induced polyploidy in Phalaenopsis orchid, Plant Cell Tissue and Organ Culture. 1: pp. 103-107. http://dx.doi.org/10.1007/BF02318909 
Griesbach, R.J. (1985). Poliploidy in Phalaenopsis orchid improvement, Journal of Heredity. 76: pp. 74-75. http://images2.wikia.nocookie.net/orchids/en/images/2/28/Polyploidy_in _ Phalaenopsis_Orchid_Improvement.pdf. 27.12.2012.

Heping, H., Shanlin, G., Lanlan, C., Xiaoke, J. (2008). In vitro induction and identification of autotetraploids of Dioscorea zingiberensis, In Vitro Cellular and Developmental Biology. 44: pp. 448-455. http://dx.doi.org/10.1007/s11627-008-9177-3

Jaskani, M.J., Kwon, S.W. and Kim, D.H. (2005). Comparative study on vegetative, reproductive and qualitative traits of seven diploid and tetraploid watermelon lines, Euphytica. 145: pp. 259-268. http://dx.doi.org/10.1007/s10681-005-1644-x

Kerdsuwan, N. and Te-chato, S. (2012). Effects of colchicine on survival rate, morphological, physiological and cytological characters of chang daeng orchid (Rhynchostylis gigantea var. rubrum Sagarik) in vitro, Journal of Agricultural Technology. 8(4): pp. 1451-1460. http://www.ijat-aatsea.com/pdf/v8_n4_12_July/25_IJAT_2012_8_4_Nattaporn $\% 20 \% 20$ Kerdsuwan-plant\%20science-accepted.pdf. 27.12.2012.

Kun-Hua, W., Jian-Hua, M., He-Ping, H. and Shan-Lin, G. (2011). Generation of autotetraploid plant of ginger (Zingiber officinale Rosc.) and its quality evaluation, Pharmacognosy Magazine. 7(27): pp. 200-206. http://dx.doi.org/10.4103/0973-1296.84230

Liu, G., Li, Z. and Bao, M. (2007). Colchicine-induced chromosome doubling in Platanus acerifolia and its effect on plant morphology, Euphytica. 157: pp. 145-154. http://dx.doi. org/10.1007/s10681-007-9406-6. 09.09.2014.

Miguel, T.P. and Leonhardt, K.W. (2011). In vitro polyploid induction of orchids using oryzalin, Scientia Horticulturae. 130: pp. 314-319.

Nakasone, H.Y. (1960). Artificial induction of polyploidy in orchids by the use of colchicines. Ph.D. dissertation, University of Hawaii, Hawaii. http://scholarspace.manoa. hawaii.edu/ bitstream/handle/10125/11486/uhm_phd_6004660_r.pdf?sequence=1. 7.12.2012.

Omidbaigi, R., Mirzaee, M., Hassani, M.E., Moghadam, M.S. (2010). Induction and identification of polyploidy in basil (Ocimum basilicum L.) medicinal plant by colchicine treatment, International Journal of Plant Production. 4(2): pp. 87-98.

Petersen, K.K., Hagberg, P. and Kristiansen, K. (2003). Colchicine and oryzalin mediated chromosome doubling in different genotypes of Miscanthus sinensis, Plant Cell, Tissue and Organ Culture. 73: pp. 137-146.

Rahayu, E.M.D. (2014). Polypoid induction of Phalaenopsis amabilis (L.) Blume and Phalaenopsis amboinensis J.J. Smith with colchicine by in vitro and in vivo techniques. MSc. thesis, Bogor Agricultural University, Bogor.

Sarathum, S., Hegele, M., Tantiviwat, S. and Nanakorn, M. (2010). Effect of concentration and duration of colchicine treatment on polyploidy induction in Dendrobium scabrilingue L, European Journal of Horticultural Science. 75(3): pp. 123-127. http://botany.sci.ku.ac.th/ upload/content/file/th/20101031012631.pdf. 03.12.2012. 
Takamura, T. and Miyajima, I. (1996). Colchicine induced tetraploids in yellow-flowered cyclamens and their characteristics, Scientia Horticulturae. 65: pp. 305-312. http://www. academia.edu/7152186/1-s2_0-0304423896008965-main. 08.09.2014.

Torres, V.R., Godina, F.R., Pournavab, R.F., Mendoza, A.B., Guzmán, G.H. and Valdés, M.H.R. (2011). Development of tomatillo (Physalis ixocarpa Brot.) autotetraploids and their chromosome and phenotypic characterization, Breeding Science. 61: pp. 288-293. http:// dx.doi.org/10.1270/jsbbs.61.288

Wu, H., Zheng, S., He, Y., Yan, G., Bi, Y. and Zhu, Y. (2007). Diploid female gametes induced by Colchicines in Oriental lilies, Scientia Horticulturae. 114: pp. 50-53. http://dx.doi. org/10.1016/j.scienta.2007.04.004. 09.09.2014.

Wu, Y., Yang, F., Zhao, X. and Yang, W. (2011). Identification of tetraploid mutants of Platycodon grandiflorus by colchicine induction, Caryologia. 64(3): pp. 343-349. http://www.caryologia. unifi.it/past_volumes/64_3/1710.pdf. 08.09.2014.

Yulianti, F., Purwito, A., Husni, A. and Dinarty, D. (2014). In vitro induction of tetraploid in Simadu tangerine (Citrus nobilis Lour) shoot-tip using colchicine, Indonesian Journal of Agronomy. 42(2): pp. 144-150.

Zhang, Z., Dai, H., Xiao, M. and Liu, X. (2008). In vitro induction of tetraploids in Phlox subulata L, Euphytica. 159: pp. 59-65. http://dx.doi.org/10.1007/s10681-007-9457-8 